\begin{tabular}{|l|l|l||}
\hline \multicolumn{2}{|c|}{ PublisherInfo } \\
\hline \hline PublisherName & $:$ & BioMed Central \\
\hline \hline PublisherLocation & $:$ & London \\
\hline \hline PublisherImprintName & $:$ & BioMed Central \\
\hline \hline
\end{tabular}

\title{
Ras signaling in Drosophilaoogenesis
}

\begin{tabular}{|l|l|l||}
\hline \multicolumn{2}{|c|}{ ArticleInfo } \\
\hline \hline ArticleID & $:$ & 4315 \\
\hline \hline ArticleDOI & $:$ & $10.1186 /$ gb-2002-3-2-reports0008 \\
\hline \hline ArticleCitationID & $:$ & reports0008 \\
\hline \hline ArticleSequenceNumber & $:$ & 16 \\
\hline \hline ArticleCategory & $:$ & Paper report \\
\hline ArticleFirstPage & $:$ & 1 \\
\hline \hline ArticleLastPage & $:$ & 4 \\
\hline \hline & & RegistrationDate : 2001-12-3 \\
ArticleHistory & $:$ & Received \\
\hline ArticleCopyright & $:$ & BioMed Central Ltd2002 \\
\hline \hline ArticleGrants & $:$ & \\
\hline \hline
\end{tabular}




\begin{tabular}{|c|c|}
\hline ArticleContext & 130593322 \\
\hline
\end{tabular}

\section{Chris Berrie}

\section{Abstract}

Dorsoventral patterning in Drosophila oogenesis reveals new links between Ras 1 and genes involved in signaling and cytoskeletal organization

\section{Significance and context}

Rasl is the Drosophila homolog of the mammalian transforming genes Ha-Ras, Ki-Ras and N-Ras. In mammals the Ras superfamily of GTPases is larger than in Drosophila - there are around 19 members, which represent some $20 \%$ of the superfamily of small GTP-binding-proteins. These proteins are known to act as molecular switches that transduce upstream signals to downstream effectors. Mutation of the three human Ras genes has been seen in some $30 \%$ of all human cancers, and many further cancerrelated signaling pathways have been shown to involve aberrant Ras function. Through a genetic analysis of the much simpler Ras1 signaling pathway in Drosophila, Schnorr et al. have identified new signaling and cytoskeletal interactions that should provide information on the function of their mammalian counterparts.

\section{Key results}

Using a dominant modifier screen in Drosophila, the authors have identified genes that enhance a weak Ras1 aberrant phenotype during oogenesis. Three of these mutant 'Ras1 Enhancers' represent known proteins involved in Ras1 signaling pathways in Drosophila: the EGF receptor (Egfr); Star, a single-pass transmembrane protein that is required for EGF signaling; and Blistered, a transcription factor that is dependent on the function of the receptor tyrosine kinases Breathless and Egfr. Seven other identified genes encode proteins involved in cell signaling and the regulation of the cytoskeleton, but which have not been linked to this Ras1 pathway before: Chickadee, Tec29, Dreadlocks, POSH, Peanut, Smt3 and MESK2. Of the two remaining Ras1 Enhancers, one maps to an overlapping region containing genes for a putative receptor tyrosine kinase, Nrk, and a protein that is thought to be involved in the degradation of neuropeptides, TppII. The final one lies within four candidate genes, one showing homology with the Notch and Delta family of cell adhesion molecules, and the other three encoding proteins of no known function. Schnorr et al. have also identified five lines with the Rasl Enhancer phenotypethat are independent of the Ras 1 mutation, and instead involve the $\operatorname{Sec} 61 \beta$ gene, which codes for a putative protein translocation channel. 


\section{Methodological innovations}

With the help of the Berkeley Drosophila Genome Project (BDGP), Schnorr et al. have combined the standard technique of genetically-engineered $\mathrm{P}$ transposable elements inserted in genomic regions with the generation of a weak Ras 1 allele that provides a threshold for adequate signaling through this pathway. The extent of the Ras 1 phenotype was assessed by studying defects in eggshell formation. They conducted a breeding scheme to introduce these mutations into the weak Ras 1 background, followed by a genetic screen to find heterozygous mutations that enhanced the phenotype - the Ras 1 Enhancers.

\section{Reporter's comments}

This is essentially a study of the functions that can be linked to the Ras 1 Enhancer genes (and hence their protein products) in Drosophila. Initially, identification of two known Ras 1 pathway components in oogenesis - Egfr and Star - as Ras 1 Enhancers demonstrates the efficacy and suitability of Schnorr and colleagues' approach. The Blistered gene is also known to be part of the Ras1 signaling pathway, although its previously demonstrated function in wing development indicates a different form of regulation from that described here. In addition to these known interactions, this study identifies other potential Ras 1 interactors in dorsoventral patterning in Drosophila oogenesis. Thus, Dreadlocks, Tec29 and POSH are revealed as new members of this Egfr/Ras1-regulated developmental pathway. At the same time, and in conjunction with Chickadee, Peanut and Smt3, they are also now seen to be involved in the regulation of the cytoskeleton, which itself is shown to be crucial in Drosophila oogenesis.

A further benefit of this work is its potential bidirectionality - the mammalian system can indicate functions of the Drosophila Ras 1 Enhancers and vice versa. The mammalian homologs of POSH, Chickadee and Peanut have previously been implicated in cytoskeletal reorganization, and this study confirms these interactions. Similarly, the mammalian counterpart of Nck is known to interact with Sos, an interaction that has not previously been shown for the Drosophila Nck homolog, Dreadlocks, which has instead been linked to Misshapen and Pak through neuronal development. These points are also discussed in further detail by the authors.

Certain questions remain that will help to identify further interactors of both Drosophila and mammalian proteins. Is Nrk or TppII the true Ras1 Enhancer (the authors provide arguments for both), and what of the two novel genes identified in this system? Finally, although Schnorr et al. have used the ability to suppress activated Egfr to show that Dreadlocks and Smt3 operate downstream of Egfr, the full profile of the involvement of the remainder of the Ras1 Enhancers in this, and other, Ras1 signaling pathways still needs to be determined.

\section{Table of links}


Genetics

\section{References}

1. Schnorr JD, Holdcraft R, Chevalier B, Berg CA: Ras 1 interacts with multiple new signaling and cytoskeletal loci in Drosophila eggshell patterning and morphogenesis. Genetics. 2001, 159: 609-622. 0016-6731

This PDF file was created after publication. 